\title{
EXCHANGE RATE RISK IN ALBANIA - CALCULATING VaR USING MONTE CARLO SIMULATION
}

\author{
Teuta Xhindi ${ }^{1}$ \\ Ermela Kripa $^{2}$
}

DOI: https://doi.org/10.31410/ERAZ.S.P.2019.227

\begin{abstract}
Risk management is one of the most important processes of all agents operating in the financial and non-financial markets. It is the combination of three steps: risk assessment, emission and exposure control and risk monitoring. As of the assessment step, the VaR model is the most common approach used to measure the market value at risk.
\end{abstract}

The aim of this paper is to evaluate the performance of the VaR model, in measuring the relative risk in the Albanian foreign exchange market, where future prices in foreign exchange market are calculated using the Monte Carlo simulation. In our analysis, we have considered the coefficient of variation a good tool in measuring relative risk. The utilized data is taken from the official website of the Bank of Albania, corresponding to the daily rates of exchange in the Albanian foreign exchange market of January 3, 2018 to January 3, 2019. The instrument used is the simple linear regression, where the dependent variable is VaR and the independent variable is the coefficient of variation.

The result of the study is: The VaR Model isn't a good instrument to measure the exchange rate risk in our case.

Keywords: Value at Risk, Coefficient of Variation, Monte Carlo simulation, Simple Linear Regression.

\section{INTRODUCTION}

$\mathrm{M}_{\mathrm{c}}$ easuring the financial risk has become one of the main objectives of the vast majority of actors operating in the market. It is very important to identify and measure different categories of risks that characterize companies and various transactions in the financial market, and not only. Many transactions are characterized by market risks. An example of that is the exchange rate risk, which is one of the most important market risks. Measurement and risk assessment models are numerous and have evolved over time. Although the corresponding models are numerous, in this paper we will use the VaR model to measure the exchange rate risk.

But what is the definition of the Value at Risk?

When making investment decisions, an investor has to seek a balance between risk and return. The theory of portfolio selection dates back to Markowitz's theory in 1952 [1] and continues with modern theories. In his theory, Markowitz took the variance of his portfolio into a single period as a measure of risk. This indicator has its own limitations as the variance is a symmetrical measure and does not take into consideration the direction of the movements. To address this problem, alternative risk measures such as Value at Risk and Conditional Value at Risk have been introduced to replace the variance. 
The mathematics that underlie VaR were largely developed in the context of portfolio theory by Harry Markowitz and others, though their efforts were directed towards a different end - devising optimal portfolios for equity investors. In particular, the focus on market risks and the effects of the co - movements in these risks are central to how the VaR is computed.

Below, some definitions for the VaR given by different authors are presented.

Value at risk (VaR) summarizes the worst loss of a portfolio over a given period with a given level of confidence [2]. Hull [3, p. 477] defines VaR as 'a loss that will not be exceeded at some specified confidence level'. Many researchers and financial agents usually use VaR by numerical approximations since the VaR portfolios analyze is not easy mathematically [4]. Based on several approaches, we can say that VaR is a risk sensitive indicator based on percentiles and is one of the standard criteria used in asset management.

VaR has become widely used by financial institutions, corporations and asset managers [5]. The Basle Committee on Banking Supervision (BIS) and other central bank regulators also use VaR as a benchmark risk measure to determine the minimum amount of capital a bank is required to maintain as reserve against market risk [6]. There are some methods to calculate option portfolio VaR. The most widely used is the Delta normal method.

The historical simulation method uses data on daily returns to determine a VaR value and this model makes no assumptions regarding the statistical distributions of these returns. The method used in this paper for measuring VaR is the Monte-Carlo Simulation.

For the calculation of $\mathrm{VaR}$, in addition to the historical simulation method, the Monte Carlo simulation is used. In this case, the future values series of the foreign currency-to- Albanian lek exchange rate are generated based on this equation:

Today value of exchange rate $=$ Yesterday value of exchange rate $\times e^{X}$

Where, $X$ is the random variable with theoretical normal distribution.

This formula was proposed and applied for the first time by the French mathematician Louis Bachelier, the first to model the stochastic process called the Brownian motion.

On the other hand, nonetheless all the debates, the coefficient of variation is mainly used as a relative risk measure, in comparative cases when we have to choose between different opportunities for investing.

Mathematically, the coefficient of variation is calculated through the formula:

$$
\mathrm{CV}=\sigma / \mu \times 100 \%
$$

Where: $\sigma$ is the standard deviation of all observations and $\mu$ is their mean.

The coefficient of variation is a measure of volatility in the exchange rate market. Sometimes it is more preferable than the standard deviation (or variance), especially in cases when is important to identify the quickly changing periods of exchange rates. 
In this paper we want to test whether the VaR, calculated with the Monte Carlo simulation, is a good method for measuring risk in the foreign exchange market in Albania, assuming that the coefficient of variation is.

In order to investigate the goodness of using VaR, calculated with the Monte-Carlo simulation, in the foreign exchange market in Albania, we will make the simple linear regression in which as the independent variable we will use the coefficient values of the variation for the 13 currencies, the exchange rates of which are available on the official website of the Bank of Albania, and as a dependent variable we will use VaR data for these currencies. The confidence level used in this paper is $95 \%$.

\section{THE OBJECTIVE, THE RESEARCH QUESTION AND HYPOTHESIS}

The objective of this paper is to test for the goodness of using VaR, calculated with Monte Carlo simulation, for measuring the risk in the foreign exchange market in Albania.

\section{The research question:}

Is VAR calculated with Monte-Carlo simulation a good instrument to measure risk in the Albanian exchange market when we accept that the coefficient of variation is?

\section{Hypothesis:}

There isn't a statistically significant relationship between the coefficient of variation and VaR calculated with Monte Carlo simulation.

\section{THE METHODOLOGY AND DATA COLLECTION}

The currencies taken into consideration are: US Dollar, Euro, Great Britain Pound, Swiss Franc, Japanese Yen (100), Australian Dollar, Canadian Dollars, Swedish Krona, Norwegian Krone, Denmark Krone, Special Drawing Rights, Gold (OZ 1), Silver (OZ 1).

The utilized data is taken from the official website of the Bank of Albania.

Based on the daily rates of exchange data for 13 foreign currencies - lek over a year from January 3, 2018 to January 3 2019, we calculate:

- The daily periodic return, based on formula $X=\ln \left(\mathrm{P}_{1} / \mathrm{P}_{0}\right)$, where $\mathrm{P}_{0}$ and $\mathrm{P}_{1}$ are respectively rates of exchange in two consecutive days.

- The mean, variance and standard deviation for values of daily periodic return.

We rely on the following equation to generate with Monte Carlo simulation the future values for exchange rates for every currency:

Today value of exchange rate $=$ Yesterday value of exchange rate $\times e^{X}$, where $X$ is the daily periodic return.

The Monte Carlo simulation generates the future theoretical values of $X$, that is a random variable with theoretical normal distribution. To model the motion and to determine the probable future values of random variable $X$, we have used an equation that models the random motion. 
This equation was proposed and used for the first time a hundred years ago from Louis Bachelier, the first mathematician to model the stock prices similarly with the Brownian motion. The stochastic process named Brownian motion assumes that there are two parts on the amount of change in the exchange rate:

- The deterministic part,

- The random part or random stochastic variable.

The daily periodic return $X$ can be modeled as follows:

$$
X=\ln \left(\mathrm{P}_{1} / \mathrm{P}_{0}\right)=\mu+\sigma \mathrm{z}_{\mathrm{t}}
$$

Where:

$\mu$ - the deterministic part, the expected periodic return daily value,

$\sigma$ - the random part, random shock.

From the sample data, we have calculated the mean and variance of periodic daily return for one-year exchange rate data as estimators of $\mu$ and $\sigma^{2}$.

The calculation of the random part $z_{t} \sigma$, is done by multiplying the standard deviation of periodic daily return for one-year exchange rate data with normal standard values, generated from random selection of different probability levels.

After calculation of $X$, the formula below is used:

Today's value of exchange rate $=$ Yesterday value of exchange rate $\times e^{X}$, to generate the future price values in the foreign exchange market.

We have generated the future values from 04th January 2019 till 30th September 2019.

In figures 1 and 2, the histograms of frequency distribution for daily return for two main currencies in the Albanian foreign exchange market: euro and dollar are given.

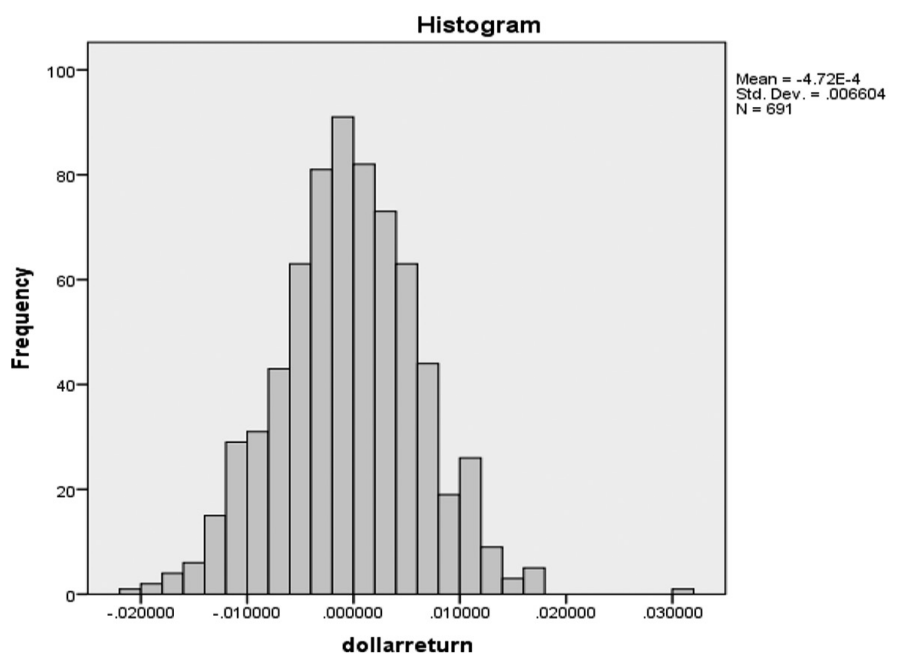

Figure 1: Histogram of frequency distribution for daily return data for dollar/lek 


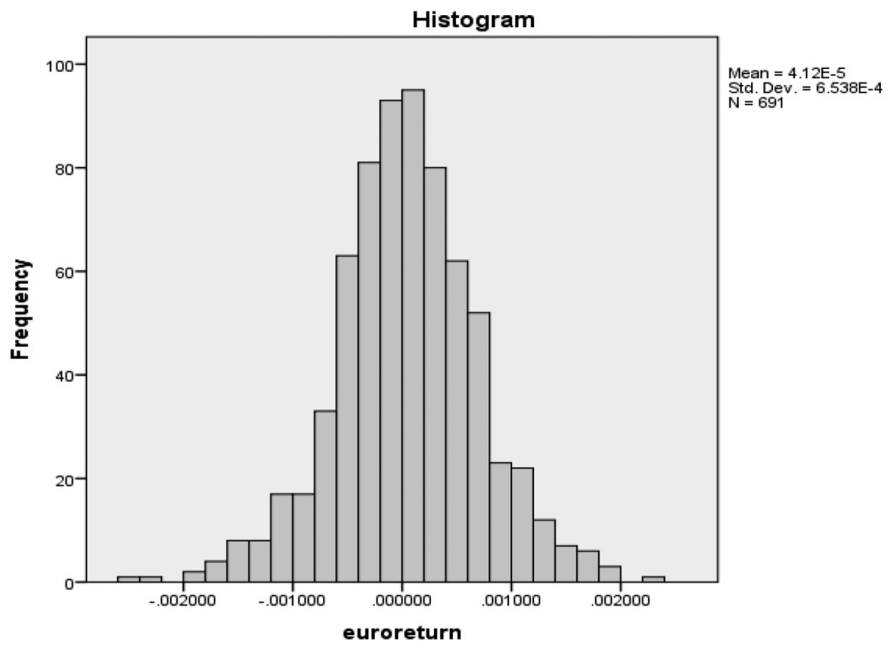

Figure 2: Histogram of frequency distribution for daily return data for euro/lek

After the data were generated, for every exchange rate foreign currency series, the periodic daily return and coefficient of variation were calculated (the later by formula $\mathrm{CV}=\sigma / \mu$ ).

Also, from these data, after ranking the return value series from smallest to largest, the VaR was calculated as a 5\% percentile of the daily return values * 1.000.000.000 ALL (since we chose the $95 \%$ confidence level).

The results from these calculations are presented in the table below:

Table 1: The values mean, standard deviation, coefficient of variation and $\mathrm{VaR} /$ million for all data

\begin{tabular}{|l|c|c|c|c|}
\hline Currencies & Mean & Standard Deviation & CV & $\begin{array}{c}\text { VaR Monte-Carlo/ } \\
\text { million }\end{array}$ \\
\hline US Dollar & -0.00047 & 0.0066 & -13.98579 & -11398968.19 \\
\hline Euro & $4.11687 \mathrm{E}-05$ & 0.00065 & 15.87036 & -1034217.789 \\
\hline Great Britain Pound & 0.00016 & 0.00535 & 32.59422 & -8854421.252 \\
\hline Suisse Franc & 0.00022 & 0.01032 & 46.59688 & -14695155.23 \\
\hline Japanese Yen (100) & -0.00021 & 0.00615 & -28.71541 & -10058024.92 \\
\hline Australian Dollar & 0.00020 & 0.00707 & 35.61717 & -11310054.55 \\
\hline Canadian Dollar & 0.00027 & 0.00699 & 25.87578 & -11085364.55 \\
\hline Swedish Krona & $4.88632 \mathrm{E}-05$ & 0.00485 & 99.32108 & -7968257.484 \\
\hline Norwegian Krone & $9.48651 \mathrm{E}-05$ & 0.00728 & 76.73549 & -11649793.76 \\
\hline Denmark Krone & $2.20002 \mathrm{E}-05$ & 0.00100 & 45.49423 & -1602136.981 \\
\hline Special Drawing Rights & -0.00017 & 0.00713 & -42.58421 & -12326599.71 \\
\hline Gold (OZ 1) & -0.00051 & 0.00900 & -17.53719 & -15521462.73 \\
\hline Silver (OZ 1) & 0.00051 & 0.01493 & 29.24483 & -23641977.1 \\
\hline
\end{tabular}

Below, a summary of the steps for calculation of variables before performing regression analysis:

1. Download the prices of exchange rates for a one-year period,

2. Calculate the daily periodic return by formula: $X=\ln \left(\mathrm{P}_{1} / \mathrm{P}_{0}\right)$, where $\mathrm{P}_{0}$ and $\mathrm{P}_{1}$ are the prices in two consecutive days,

3. Calculate the mean, variance and standard deviation of daily periodic returns,

4. Model the return values $X$ by equation: $X=\mu+\sigma \times \operatorname{normsinv}(\operatorname{rand}())$,

5. Calculate the future values of exchange rates by equation:

Today value of exchange rate $=$ Yesterday value of exchange rate $\times e^{r}$,

6. Calculate the values of coefficient of variation and VaR for each currency. 
From these calculations, we obtain the values for the dependent variable VaR and for the independent variable $\mathrm{CV}$, necessary for the regression analysis.

\section{THE INTERPRETATION OF RESULTS}

We set the null and alternative hypothesis:

$H_{0}$ : There is not a significant relationship between VaR and the coefficient of variation

$H_{a}$ : There is a significant relationship between VaR and the coefficient of variation

The tables below are obtained from the output of IBM SPSS Statistics 20:

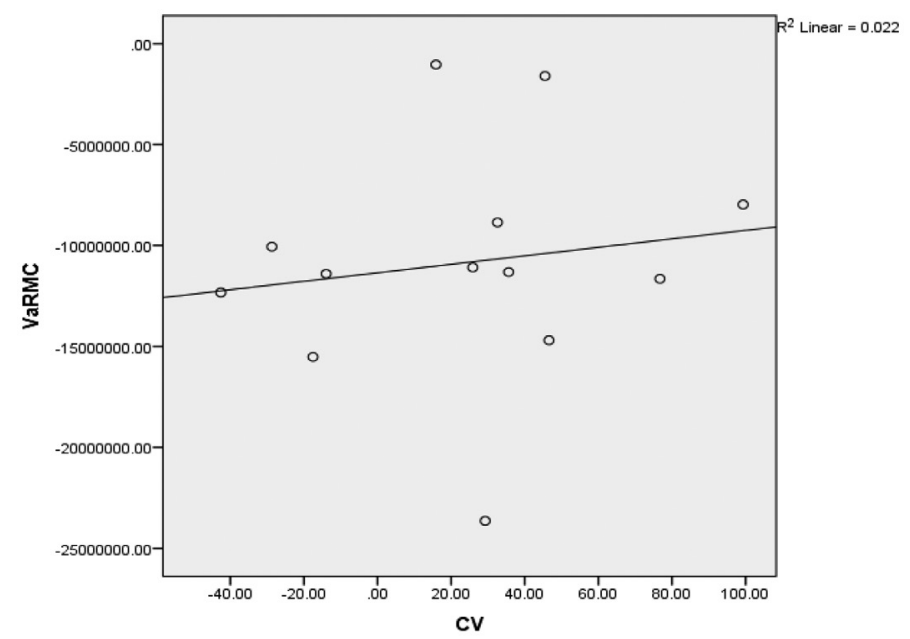

Figure 3: The scatterplot for the linear relationship between VaR and coefficient of variation

Below are the results of Kolmogorov - Smirnov and Shapiro - Wilk normality tests for both variables.

$H_{01}:$ The values of Coefficient of Variation are normally distributed,

$H_{02}:$ The values of VaR are normally distributed.

Table 4: The normality tests for the variables VaR and CV

\begin{tabular}{|l|l|l|l|l|l|l|}
\hline \multicolumn{7}{|c|}{ Results of Tests of Normality } \\
\hline \multirow{2}{*}{ Variables } & \multicolumn{3}{|c|}{ Kolmogorov - Smirmov } & \multicolumn{3}{c|}{ Shapiro - Wilk } \\
\cline { 2 - 8 } & Statistic & df & Sig. & Statistic & df & Sig. \\
\hline CV & 0.139 & 13 & 0.2 & 0.964 & 13 & 0.82 \\
\hline VaRMC & 0.169 & 13 & 0.2 & 0.92 & 13 & 0.254 \\
\hline
\end{tabular}

As the $p$ values in both cases are greater than $\alpha=5 \%$, we conclude that the two variables are normally distributed.

The table below presents some statistics from the output of simple linear regression with dependent variable VaR calculated with Monte Carlo simulation and independent variable coefficient of variation.

Table 5: Some statistics from the output of the regression analysis

\begin{tabular}{|c|c|c|c|c|}
\hline Correlation & R-square & Durbin-Watson & Test statistic & $\mathrm{p}$-value \\
\hline 0.149 & 0.022 & 1.406 & 0.501 & 0.626 \\
\hline
\end{tabular}

From the output, as the p-value $=0.626>\alpha=0.05$, we can't reject the null hypothesis. 
At $\alpha=0.05$ level, we conclude that there isn't significance relationship between the coefficient of variation and VaR calculated with the Monte-Carlo simulation. This means that the VaR model is not a valid methodology for risk calculation in the Albanian exchange market, assuming the coefficient of variation is.

\section{CONCLUSION}

In this paper, using the regression analysis we have proved that the VaR model is not a good instrument to measure the relative risk in the Albanian exchange market, when we assume that the coefficient of variation is. The VaR was calculated from simulated exchange rate values, using the prices of exchange rate for one-year period and the formula:

\section{Today value of exchange rate $=$ Yesterday value of exchange rate $\times e^{r}$}

\section{REFERENCES}

[1] Markowitz, H. (1952), "Portfolio Selection", The Journal of Finance, Vol. 7, No. 1. (Mar., 1952), pp. 77-91, taken in: https://www.math.ust.hk/ maykwok/courses/ma362/07F/markowitz JF.pdf

[2] Jorion, P. (2000). "Value at Risk", 2 editions, McGraw-Hill, New York at al.

[3] Hull, J.C. (2007). Risk management and financial institutions. Upper Saddle River, NJ: Pearson Prentice Hall.

[4] Julijana, A. (2013). Managing market risk with VaR (Value at Risk). Management, 18(2): 81-96.

[5] Morgan, J. (1996), "Risk Metrics", Technical document, Morgan Guaranty Trust Company

[6] Pallota, M. \& Zenti, R. (2000), "Risk analysis for asset managers: Historical simulation, the bootstrap approach and value at risk calculation", working paper, RAS Asset Management.

\section{ADDITIONAL READINGS}

Berkowitz, J., (2002), “How Accurate are Value-at-Risk Models at Commercial Banks?”, The Journal of Finance, Volume 57 Issue 3, p. 1093-1111.

Brief R.P. \& Joel O., (1969), “A note on Earnings Risk and the Coefficient of Variation”, Journal of Finance, Volume 24, issue 5, fq. 901-904, American Finance Association.

Cassidy, C. \& Gizycki, M. (1997). "Measuring traded market risk: value-at-risk and backtesting techniques”. Research Discussion Paper 9708, Bank Supervision Department Reserve Bank of Australia.

Dewitt R. \& Charles dhe Edna N.R., (1970), "Exact Determination of Earnings Risk by the Coefficient of Variation", Journal of Finance, volume 25, issue 5, fq.1161-1165, American Finance Association.

Gitman L.J., (1990), "Fundamentals of Investing", Boston: Pearson Education.

Gitman L.J., (2007), "Principles of managerial finance“, Boston: Pearson Education.

Jorion, P. (2000). "Value at Risk", two editions, McGraw-Hill, New York at al.

Jorion, P. (2006). Value at risk: The new benchmark for managing financial risk. New York: McGraw-Hill.

Perez, P., G., \& Murphy, D. (2015), “Filtered historical simulation Value-at-Risk models and their competitors", Working Paper No. 525, Bank of England.

Sironi, A., (2006), "Rischio e Valore nelle Banche: Risk Management e Capital Allocation, Egea", Prima Ristampa, p.103-109. 